\title{
THE IMPORTANT PRINCIPLES AND FACTORS FOR SIGNIFICANT DEVELOPMENTAL OUTCOMES: THE ROLE OF EXPERIENCE, AGE, DEVELOPMENTAL STAGES, AND SOCIOCULTURAL CONTEXT IN HUMAN DEVELOPMENT
}

\author{
Malathie Dissanayake* \\ South Asian Institute of Technology and Medicine, Sri Lanka
}

\begin{abstract}
Human development is a process of growth and change that begins at conception and continues throughout the life span. It involves changes in biological, socioemotional, and cognitive domains that are inextricably intertwined. These changes are crucial for children to function successfully in their living environment. An enormous amount of research has indicated that both prenatal and postnatal experiences, microsocial as well as macrosocial interactions, and sociocultural factors significantly influence the process of development. Also, it has been observed that new ways of understanding and responding to the world emerge at particular times in life; therefore, certain ages are crucial for the growth and changes of major domains of human development. According to developmental psychologists, behavior is not a context-free phenomenon; instead, it is a product of an interaction between the individual and his socio-cultural context. Therefore, many theorists have highlighted the importance of understanding the process of development and human behavior within the sociocultural context in which people live. The purpose of this paper is to discuss important principles and factors including prenatal and postnatal experiences, developmental changes in particular stages in life, and socio-cultural factors that significantly contribute to the process of development.
\end{abstract}

Keywords: human development; prenatal and postnatal experiences; stages of development; sociocultural context

\section{Introduction}

Human development is the process of a human becoming a biologically, psychologically and socially mature person. The purpose of this process is to expand human capabilities that help individuals successfully engage in their environment. The process of human development begins at conception and continues throughout the life span. The growth and changes in biological, social, emotional, personality and cognitive domains are crucial for a child to adapt to his environment in an attempt to continue his life. Therefore, the changes in the aforementioned areas are vital for him to enhance his abilities in order to successfully function in his social world. This paper will discuss some important principles and factors such as experience, age, developmental stage, and sociocultural context that significantly contribute to developmental outcomes.

\section{Importance of Experience}

Research suggests that both prenatal and postnatal experiences significantly influence the process of child development. Though these experiences are crucial for the development, different experiences may lead to different developmental trajectories as well as developmental outcomes. As a result, some children and adolescents may be more vulnerable to certain developmental outcomes that obstruct successful development. 
Experiences received during the prenatal environment are crucial for child development. The organism reacts to the state of the mother as well as the significant environmental inputs he receives in the uterus (Coe \& Lubach 2008). These stimulations have an effect on the maturation of different systems such as immune, nervous, and endocrine systems of the organism. Experiences received during the prenatal development also influence programming the regulatory set points that control physiological conditions in later life. The biological processes that occur during prenatal development lead the developmental process towards either healthy or abnormal outcomes (Coe \& Lubach 2008).

\section{Gene-environment Interaction}

Gene-environment interaction, probabilistic epigenesis, and ecological systems are three ways in which experience functions in the process of human development. They help us gain a better understanding of the importance of experience in human development. Considering the gene- environment interaction, research has suggested that certain genes modify the effect of the environment on human development. The timing and the pattern of genetic expression in specific tissues have an impact on phenotypic effects. Environmental experiences may influence the genetic expression, thereby having long-term effects on the individual's behavior (Rutter, 2006). Further, previous studies have indicated that particular environmental experiences influence genetic expressions in specific body tissues in certain parts of the brain (Rutter, 2006). There is also evidence that prenatal as well as postnatal environmental effects combined to generate clear differences in behavior (Rutter, 2006). The prenatal environmental influences prepare the organism to react to the postnatal environment in a particular manner. Considering the language development, for example, though infants exhibit the ability to discriminate different sounds during the first six months, it changes during the middle of the first year due to the exposure to their language environment. For example, Japanese people seem to have difficulty in discriminating between ' $R$ ' and ' $L$ ' sounds since they do not experience this differentiation in their language environment. This suggests the environmental influences have profound effects on language development.

\section{Probabilistic Epigenesis}

Probabilistic epigenesis explains the reciprocity of influences, both in internal and external environments, on the organism. The metatheoretical model of probabilistic epigenesis includes four levels of analysis: genetic activity; neural activity; behavior; and the physical, social, and cultural aspects of the environment. Further, it emphasizes the bidirectional effects that occur both within and between these levels as well as the importance of the gene-environment interactions in understanding the developmental process (Gottlieb, 2007). Genes cannot generate any neural or behavioral effect without interacting with the environmental inputs. Individuals with same genotypes may have different neural and behavioral outcomes as a result of being exposed to different life experiences (Gottlieb, 2007). Though the gene-environment interaction can produce both normal and abnormal outcomes, the experiential environment plays a significant role in the process of human development. Hence, psychologists highlight the importance of using the multiple gene-multiple life experience approach in conducting research rather than focusing on the one gene-one life experience approach, particularly in comprehending probabilistic epigenesis and in obtaining significant outcomes (Gottlieb, 2007).

The etiology of certain diseases begins with the fetal stage of the organism. For example, clinicians have suggested that causes for asthma can be related to prenatal stage of development (Coe \& Lubach 2008). According to them, some infants may start to react to certain plant allergens and food proteins that transfer across the placenta before birth. In fact, postnatal warning signs for asthma in some children predict later onset of allergies and skin disorders. Prenatal stress is another influential factor for certain abnormal outcomes. Prior research has indicated that maternal stress an apparent predisposition for infants' anemia, leads to abnormalities in sensitive regions of the brain (Coe et al., 2003), the size of the hippocampus, and functions in the brain and behavior (as cited in Coe et al., 2003). Further, cognitive processes such as attention, emotion regulation, 
manual dexterity and spatial navigation appear vulnerable to interruption due to maternal stress. All these findings suggest that prenatal experiences are crucial for various processes in human development.

\section{Ecological Systems}

Ecology of human development which focuses on the interactions between a human organism and the change of immediate environment in which he lives, is another important way of understanding the influence of experience on the developmental process (Bronfenbrenner, 1977). Changes of immediate environment may occur within or between different levels or systems of ecological environment: microsystem, mesosystem, exosystem, and macrosystem. Microsystem includes the dyadic relationships and interactions between a child and his immediate surrounding (Berk, 2000). Mesosystem encompasses interactions between the structures or the major settings of the microsystem (e.g., the child's teacher and the parents). Exosystem refers to the major social structures in society or the larger social system such as neighborhood, the mass media, and government agencies, wherein the child does not act directly. Macrosystem comprises the outermost layer of the child's environment, that is, the institutional patterns of the culture (e.g., cultural values, and customs) or subculture including economic, social, educational and political systems. Macrosystem influences the structures or the settings (family or workplace) where the parents function.

In the process of development, changes in one system can influence other systems in different ways. Studies on gene-environment interaction and probabilistic epigenesis have revealed that exposure to certain environmental inputs and experiences play a role in human development. The eco system approach has explained how particular events change different levels of eco system and how these changes affect one's developmental process. Hence, it is important to understand the effects of experiences or exposure to certain environmental inputs that affect infants to adapt to their social environment.

\section{Real-time Processes}

Both microsocial (moment-to-moment/real-time) and macrosocial (developmental) time scales are important in the developmental process of children as well as adolescents since they go through different life experiences as a result of biological and psychosocial changes. Studies have highlighted the role of moment-to-moment or microsocial interactions in human development (Granic \& Patterson, 2006). Particularly, moment-to-moment or day-to-day experiences seem to have an effect on the emergence of antisocial outcomes. Real-time family and peer processes have been identified as influential mechanisms that may affect macrosocial developmental outcomes. Bronfenbrenner and Morris's (1998) bioecological theory states that proximal processes such as family and peer interactions that operate over time are the basic components of the developmental process (Granic \& Patterson, 2006).

Studies on interactions between parents and children in natural settings have provided evidence for the effects of real-time experience on children's and adolescents' behavioral outcomes. In order to gain a better understanding of developmental outcomes of real-time direct experiences, Patterson and his colleagues $(1982,1992)$ examined the parent-child interactions with at-risk youth. Using the sequential analysis of microsocial interactions, they revealed how parents' behavior patterns encourage aggressive and antisocial behavior of their children. Accordingly, an aggressive child is likely to receive aversive responses or interruptions (e.g., mother's command in an irritable voice) from a family member once every three minutes. These behaviors have bidirectional effects; the child tends to react to it aggressively and, as a result, the family member (e.g., the parent) would be frustrated and gives up the child's coercive behavior. When children experience these types of behavior patterns more often they will be repeatedly reinforced and, consequently, they exhibit antisocial outcomes (Patterson, 1982; Snyder \& Patterson, 1995). According to Patterson, these behavioral processes affect siblings reciprocally and reinforce their aggressive behavior as well. There is also evidence for coercive 
behaviors in children that cause long-term psychological problems (e.g., Snyder \& Patterson, 1995; Snyder, Schrepferman, \& St. Peter, 1997; Forgatch \& DeGarmo, 2002).

Additionally, the dynamic system approach emphasizes the value of both external factors and internal mechanisms (e.g., emotions) of the individual that affect the real-time interactions reciprocally (Granic \& Patterson, 2006). Emotional developmentalists have stated that emotions and cognitive appraisals considerably influence an individual's global personal structure. Some theorists have described the link between emotions and cognitive processes as a feedback loop (e.g., Teasdale \& Barnard, 1993; Lewis, 1995, 1997). According to them, emotions lead one's attention to specific goal-directed components in a given situation and cognitiveemotion structures are viewed as personality specific interactions between a parent and a child. Lewis (1995, 1997) believed that parent-child emotion-appraisal coupling may influence reciprocally and become a more complex combination. Anger and contempt seem to be the most relevant emotions for both parents and children in coercive interactions. The propensity of parents and boys to show contempt to one another predicts unsuccessful parental practices and antisocial behavior (Forgatch \& Stoolmiller, 1994). A study with 5-6 year old children has further suggested that angry, dismissive, and contemptuous parental reactions may lead to children's anger and may reciprocally affect their interactions leading to behavior problems in children (Synder et al. 2003).

Not only the real-time family-child interactions but also adolescent's real-time interactions with peers may lead to aggressive and antisocial behavioral outcomes. Several studies have found a relationship between deviant peer affiliation and antisocial behavior (e.g., Dishion and colleagues (1995, 1996, 1997, 1999, 2000). It seems that deviant peers reinforce each other through positive affective reactions for deviant talks such as talking about lying, stealing, and taking drugs, thereby positively encouraging one another for antisocial behavior. All this evidence suggests that real-time processes affect children in certain ages and, therefore, psychologists pay considerable attention to these factors when developing intervention programs, particularly for at-risk children.

\section{Age}

According to developmental theorists, certain ages are very important for the growth and the acquisition of skills. Theorists such as Sigmund Freud, Erik Erikson, and John Bowlby emphasized the importance of the first year of life as it is a critical period for cognitive, socio-emotional, and language development. Particularly, first two years of life are important for infants to develop basic trust (Erikson, 1950), attachment (Bowlby, 1969), language acquisition (Werker \& Desjardins, 1995), and sensory-motor skills (Lerner, 2002). Moreover, ages from 3 to 5 have been recognized as a crucial time for developmental changes in seven aspects: physical and locomotor growth, language, impulse control, social-cognitive understanding, conceptions of the self, cognitive executive processes and the desire for autonomy (as cited in Lamb \& Lewis, 2005). Research also suggests that the majority of youth in the 13-14 year age range experience dramatic developmental changes: onset of puberty (Paikoff \& Brooks-Gunn, 1991), the emergence of formal operational thinking (Inhelder \& Piaget, 1959, 1964; Keating, 1990), restructuring of emotional centers in the brain (Spear, 2000), and transition from junior or middle school to high school (Eccles, Wigfield, Midgley, Reuman, MacIver, \& Feldlaufer, 1993) that lead to various developmental outcomes.

In addition, children in certain age groups seem to be more vulnerable for certain psychological problems as they experience certain biological as well as psychological changes. For example, certain psychological disorders typically begin in late adolescence or early adulthood (Walker \& Tessener, 2008). As a consequence of biological and psychological changes that are unique to this particular developmental stage, youth in late teens and mid 20s go through very specific experiences. Arnett (2007) described this period as an emerging adulthood and proposed five major characteristics that make this period distinct from other age periods. They are, the age of identity explorations, the age of instability, the self-focused age, the age of feeling in-between, and the age of possibilities. Increase in self-esteem is another feature of this age period (Galambos, Barker, \& 
Krahn, 2006). Nevertheless, some have argued that youth in this age period experience identity issues and may not achieve social cognitive maturity that helps them understand "who they are" and their social world.

\section{Stages of Development}

New ways of understanding and responding to the world emerge at specific times in life. Developmental theorists (e.g., Freud, Erikson, and Piaget) who followed the stage approach stated that children undergo various changes in major domains of development such as cognitive, emotional, moral, and personality development in each developmental stage. Each stage has a qualitatively different structure. Wohlwill (1973) considered a developmental stage as a construct that has a structurally defined system and that is characterized by unifying set of behaviors. Developmental stages involve in a sequence of changes (Wohlwill, 1973; Campbell \& Richie, 1983); however, all sequences of changes may not occur in developmental stages. Developmental processes change quantitatively, and these quantitative changes directly or indirectly affect qualitative changes in the development during stage transitions (Wohlwill, 1969; Flavell, 1971).

Changes that children go through in each stage are important for their developmental outcomes. Particularly, the transition from one stage to another may be a critical period for both children and youth. Phase transitions are considered as periods of increased sensitivity. These transitions may affect the interactions of different systems as they are more opened to environmental changes. As a result, these transitions may have the potential to alter the path of relationships and to create an emergence of new forms of interactions. The new forms of interactions may derive either from outside the system or within the system through feedback (Granic \& Patterson, 2006).

Developmental theorists have recognized two stages: early childhood (3-5 years) and early adolescence (11-14) and their transitions, as the periods with the greatest potential for change. Stage is a period of stability followed by a period of disequilibrium (transition) in which the emerged forms are destabilized. After the period of disequilibrium, new development patterns and forms become stabilized. According to developmental theorists, transitions can have an impact on early childhood and early adolescence and the experiences gained during these transitions may lead to antisocial development (Granic \& Patterson, 2006). The birth of a sibling, parental divorce, and the beginning of day care are some phase transitions that may create new behavior patterns leading to both positive and negative outcomes in early childhood. Effective interventions in this stage are important, particularly when children go through certain changes caused by negative experiences and other disruptions (Granic \& Patterson, 2006).

Early adolescence stage is also considered as a critical period of development since young people experience new changes such as onset of puberty (Paikoff \& Brooks-Gunn, 1991), transition from middle school to high school (Eccles et al., 1993), the emergence of formal operational thinking (Inhelder \& Piaget, 1959, 1964; Keating, 1990), and restructuring of emotional centers in the brain (Spear, 2000). As a consequence of these transitional changes, adolescents may experience some developmental problems such as identity issues and they may tend to engage in certain behaviors such as drug use that lead to psychosis (as cited in Walker \& Tessener, 2008). Adolescence has been identified a time for the major trajectories of antisocial behavior. Studies have revealed that youth in this trajectory do not exhibit antisocial behavior till they reach early adolescence (Elliott, Ageton, Huizinga, Knowles, \& Canter, 1983; Farrington, 1986; Moffitt, 1990; Patterson \& Yoerger, 2002). According to Arnett (2007), youth in late adolescence may also face specific experiences such as identity exploration, feeling of instability, feeling in-between, and period of possibilities that lead to different developmental outcomes. Hence, changes in the developmental stage and stage transitions should be taken into consideration, particularly when developing interventions for children and adolescents. 


\section{Socialization and the Context of Social Relationships}

Many theorists including Freud, Erikson, and Bowlby stressed the importance of early experiences and family relationships, particularly the parent-child interaction, in the process of socialization. For example, theories on emotional development of children emphasize the quality of the infant-parent attachment since it is the foundation of the socialization process. In his theory of attachment, Bowlby (1969) introduced four stages of attachment and argued that children are biologically pre-programmed to develop attachments with others around them. Consistency of parental presence and the availability of parent during the sensitivity period (first 6 months) are crucial for newborn infants to develop attachment. Infants learn how to understand social interactions through daily experiences (e.g., Tomasello, 1999; Reddy, 2003). In this process, different parental styles may influence the infant-parent attachment and may lead to various developmental outcomes. Behaviors such as avoidance and rejection of a parent and inconsistent or unresponsive parenting may cause infants to develop a feeling of insecurity, thereby leading to negative developmental outcomes in children (as cited in Lamb \& Lewis, 2005).

The period between infancy and school years is an important time for developmental changes such as physical and locomotor growth, language, cognitive executive processes, social-cognitive understanding, conceptions of the self, the desire for autonomy, and impulse control. These changes help children to strengthen the parentchild attachment as well as to develop social relationships. Socialization plays a significant role in the development of their social relationships. Children understand and follow the rules of reciprocity in their social interactions and also they tend to act intentionally and react appropriately in these situations (as cited in Lamb \& Lewis, 2005).

Parent's gender also plays a role in the socialization process and the parent-child interaction. Researchers have found that parents tend to treat their baby girls and boys differently during the first year. Accordingly, mothers tend to engage in more pretend play with their daughters while fathers engage in physical play with their sons (Lindsey \& Mize, 2001). During the school age, mothers have a tendency to spend more time with their children compared to fathers; however, both parents have a propensity for initiating activities with their children with the same frequency. When children reach middle childhood, parents tend to adjust their demands. Research has revealed that parents have a tendency to encourage self-esteem, sense of humor and emotional stability in children at this age. Also, the influence of others such as peers, teachers, and educational institutions on the socialization process, particularly on children's social adjustment can be observed during this period (Lamb \& Lewis, 2005).

Attachment that a child develops in his early life influences his social relationships in adolescence and adulthood. Main et al. (1985, 1994) proposed three working models: autonomous, dismissive, and preoccupied, based on early memories of individuals' relationships with their parents. These models help us understand the nature of social relationships they had in adolescence. Previous research revealed that adolescents who were in secure or autonomous groups were rated by their peers as more ego resilient, less hostile, and less anxious (Kobak \& Sceery, 1988). They have also stated less distress and high social support. In contrast, adolescents who were in dismissive groups were rated by their peers as having high levels of hostility and low levels of ego resilience (as cited in Lamb \& Lewis, 2005). This suggests that early social interactions significantly influence adolescents' relationships with others in their social world.

\section{The Impact of Sociocultural Context}

The metatheoretical view of human development has emphasized seven characteristics: development as lifespan process, gains and losses, plasticity, historical embeddedness, contextualism as paradigm, mutidirectionality, and multidisciplinarity that are important in understanding the developmental process 
(Baltes, 1987). Among them, contextualism and multidisciplinarity are primary emphases, especially in relation to the sociocultural perspective of human development.

Early cross-cultural research in human development was mainly conducted based on either the organismic approach or the mechanistic approach. The organismic perspective considered human behavior as a universal phenomenon and focused on the structural (qualitative) change of human development. Accordingly, individuals are different because they go through structurally based stages that are qualitatively different. The mechanistic approach, on the contrary, emphasized the quantitative changes of human development (Baltes, Reese, \& Nesselroade, 1977). This perspective has neglected the idea that each culture has its unique social, historical, economic, political, religious, and geographical characteristics that influence human behavior. However, the contextual approach considered changes in human behavior as an outcome of both qualitative and quantitative changes or differences that depend on asynchronies and interactions between the person and the sociocultural context in which they live.

Compared to many other theorists, contextualists including Vygotsky (1978), Rogoff (1990), Cole, (1996), and Tomasello (1999) emphasized the importance of understanding human behavior within the sociocultural context. Particularly, Vygotsky and Rogoff did not believe that one's behavior is a context-free phenomenon. Instead, they considered that each culture has a unique value system that influences the process of human development. Culture is a multifaceted construct that provides rules and guidelines for human behavior by creating cultural specific values (Wong, Bond, \& Mosquera, 2008; Matsumoto et al., 2008). These values provide a structure and the order to human behavior within a given sociocultural context.

Vygotsky's sociocultural theory emphasizes the importance of social interaction in cognitive development. The major unit of analysis of the sociocultural perspective is the "activity" defined by the sociocultural environment. According to Vygotsky, there is a clear difference between behavior and an activity. Behavior is a property of an individual, whereas an activity is a sociocultural phenomenon that exists in the intermental level (between people). Vygotsky stated that the structure and the content of a particular culture influence the structure and the content of human development. Vygotsky believed activity is a form of transforming information from one generation to another, thus, more emphasis was given to the understanding of individuals' behavior within their socio-cultural contexts.

With regard to child development, Vygotsky considered children as social beings who actively participate in cultural activities that provide skills and knowledge about their own culture and the opportunity to transform this information to the next generation. Further, he introduced the idea of the zone of proximal development- the performance difference between the child's capacity of accomplishing something without support and his ability to achieve something with the support of others. He believed that, within the zone of proximal development, children need guidance from a more knowledgeable person in order to perform a given task and to achieve the goal (Sutherland, 1992).

The sociocultural perspective encompasses three important phenomena: guided participation, intersubjectivity, and scaffolding that influence children in acquiring culturally-specific skills and knowledge. Guided participation is the bridge between the child and the mother or the caregiver that transforms culturally-specific information about the activity. It occurs when there is practical goal to accomplish. During guided participation, the role of a more knowledgeable person (e.g., mother) is important in achieving the child's goal (Rogoff, 1990). The mother as a more knowledgeable person, provides a framework to the child to perform certain tasks at a higher level. In this process, the mother tends to help the child when he experiences some difficulties. Thence, the child learns how to execute the task with the help of the mother and internalizes the structure of performing that particular task. Vygotsky described this process where the intermental process (between people) becomes intramental (within person). 
During the process of guided participation, cultural tools, artifacts, values, and technologies are transformed. For example, in the mother-child interaction, the mother may use toys, diagrams or other tools that are unique to their culture. Also, certain cultural values may highlight the importance of spending time with the child. Language, a cultural tool, provides an opportunity for the mother to communicate with the child during guided participation as the child learns culturally unique patterns of language to express his ideas in accomplishing a goal. Additionally, technological, economic, and religious mechanisms of a particular culture may influence the background of the activity that takes place between the mother and the child (e.g., economic factors that directly or indirectly influence the mother to spend time with the child) (Rogoff, 1990; Rogoff, Mistry, Göncü, \& Mosier, 1993; Rogoff 2003).

Guided participation occurs in all cultures; however, certain culturally-specific patterns can be observed during guided participation in different socio-cultural milieus (Rogoff, 1990). Maya mothers in Guatemala, for example, teach their daughters to weave through guided participation. First, they show their daughters the way they weave and then, the mothers tend to adjust their daughters' activities when they improve their skills and when they are interested. In Venezuela, children learn hunting, cultivating, and fishing through guided participation. These culturally-specific patterns are transformed through different sociocultural institutions such as educational, political, economic, and religious institutions. Prior research has indicated that schooled individuals tend to use more strategies in solving problems than nonschooled individuals (Rogoff, 1990). Individuals in some cultures (e.g., East Asians) tend to use culturally-specific techniques (e.g., mental Abacus) in solving problems (Hatano \& Osawa, 1983). This suggests that different cultures use their own cultural tools to acquire knowledge and to improve skills.

Intersubjectivity, the mutual understanding between the mother/caregiver and the child during their cultural activity, is another emphasis by the sociocultural theorists. In this process, both the child and the mother tend to focus on the same object or the topic relevant to their task (joint attention) and then, the child learns the reaction of the other person and internalizes it. When the child experiences an unfamiliar or a threatening situation, he tends to seek assistance and guidance from the mother or a more knowledgeable person to solve the problem, and this was referred as social referencing.

Scaffolding, the third phenomenon stated by the sociocultural theorists, also helps children acquire culturallyspecific skills and knowledge. In this process, the mother arranges the task that needs to be performed by the child with a higher level and explains the task to the child as well as the way it should be done. When the child performs the task, the mother provides guidance and support if needed. In this process, the child learns how to perform the task with the help of the mother first and then, he internalizes the process and uses it in new situations where he can apply knowledge and skills acquired during scaffolding.

\section{Conclusion}

Considering all of the above, it is clear that the pre-and postnatal experiences, age-related life experiences, microsocial and macrosocial interactions and culturally-specific factors are vital in human development. All these experiences significantly influence a child to develop a unique personality as a person. As contexualists believed, behavior is not a context-free phenomenon; rather, it is an outcome of an interaction between a child and his socio-cultural context. Therefore, understanding major forces that contribute to the process of human development, particularly in early stages of life will help us provide guidance and support for children to improve their abilities, thereby function successfully in their social world.

\section{References}

Arnett, J. J. (2007), Emerging Adulthood: What Is It, and What Is It Good For? Child Development Perspectives, 1, 68-73.

doi:10.1111/j.1750-8606.2007.00016.x 
Baltes, P. B. (1987). Theoretical propositions of life span developmental psychology: On the dynamics between growth and decline. Developmental Psychology, 23, 611-626.

Baltes, P. B., Reese, H. W., \& Nesselroade, J. R. (1977). Life span developmental psychology: Introduction to research methods. Monterey, CA: Brooks/Cole.

Berk, L. B. (2000). Child development. Allyn \& Bacon.

Bowlby, J. (1969). Attachment. Attachment and loss: Vol. 1. Loss. New York: Basic Books.

Bronfenbrenner, U. (1977). Toward an experimental ecology of human development. American Psychologist, 32(7), 513-531. http://dx.doi.org/10.1037/0003-066X.32.7.513

Bronfenbrenner, U., \& Morris, P. (1998). The ecology of developmental processes. In R. M. Lerner (Ed.), Theorectical models of human development (5 ed., pp. 993-1028). (Handbook of Child Psychology; Vol. 1). New York: Wiley.

Campbell, R. L., \& Richie, D. M. (1983). Problems in the Theory of Developmental Sequences. Human Development, 26, 156-172.

Coe C. L., Kramer, M. Czeh B., Gould, E., Reeves, A. J., Kirschbaum, C., \& Fuchs, E. (2003). Prenatal stress diminishes neurogenesis in the dentate gyrus of juvenile rhesus monkeys. Biological Psychiatry, 54, $1025-1034$.

Coe, C. L., \& Lubach, G. R. (2008). Fetal programming: Prenatal origins of health and illness. Current Directions in Psychological Science, 17(1), 36 - 41.

Cole, M. (1996). Interacting minds in a life span perspective: A cultural/historical approach to culture and cognitive development. In P. B. Baltes \& U. M. Staudinger (Eds.), Interactive minds: Life span perspectives on the social foundation of cognition (pp. 59-87). New York: Cambridge University Press.

Dishion, T. J. (2000). Cross-setting consistency in early adolescent psychopathology: Deviant friendships and problem behavior sequelae. Journal of Personality, 68, 1109-1126.

Dishion, T. J., \& Andrews, D. W. (1995). Preventing escalation in problem behaviors with high-risk adolescents: Immediate and 1-year outcomes. Journal of Consulting and Clinical Psychology, 63,538-548.

Dishion, T. J., \& Medici Skaggs, N. (2000). An ecological analysis of monthly "bursts" in early adolescent substance use. Applied Developmental Science, 4, 89-97.

Dishion, T. J., Andrews, D. W., \& Crosby, L. (1995). Antisocial boys and their friends in early adolescence: Relationship characteristics, quality and interactional process. Child Development, 66, 139-151.

Dishion, T. J., Eddy, J. M., Haas, E., Li, F., \& Spracklen, K. M. (1997). Friendships and violent behavior during adolescence. Social Development, 6, 207-223.

Dishion, T. J., McCord, J. \& Poulin, F. (1999). When interventions harm: Peer groups and problem behavior. American Psychologist, 54, 755-764.

Dishion, T. J., Spracklen, K. M., Andrews, D. W., \& Patterson, G. R. (1996). Deviancy training in male adolescent friendships. Behavior Therapy, 27, 373-390.

Dishion, T.J., Capaldi, D. M., Spracklen, K. M., \& Li, F. (1995). Peer ecology of male adolescent drug use. Development and Psychopathology, 7, 803-824.

Eccles, J. S., Wigfield, A., Midgley, C., Reuman, D., MacIver, D., \& Feldlaufer, J. (1993). Negative effects of traditional middle schools on students' motivation. The Elementary School Journal, 93, 553-574.

Elliott, D. S., Ageton, S. S., Huizinga, D., Knowles, B. A., \& Canter, R. J. (1983). The prevalence and incidence of delinquent behavior: 1976-1980 (The National Youth Survey Rep. No. 26). Boulder, CO: Behavioral Research Institute.

Erickson, E. H. (1950). Childhood and society. New York: Norton.

Farrington, D. P. (1986). Age and crime. In M. Tonry \& N. Morris (Eds.), Crime and justice: An annual review of research (Vol. 7, 189-250). Chicago: University of Chicago Press.

Flavell, J. H. (1971). Stage related properties of cognitive development. Cognitive Psychology, 2, 421-453.

Forgatch, M. S., \& DeGarmo, D. S. (2002). Extending and testing the social interaction learning model with divorce samples. In J. B. Reid, G. R. Patterson \& J. Snyder (Eds.), Antisocial behavior in children and adolescents: A developmental analysis and model for intervention (pp. 235-256). Washington, DC: American Psychological Association. 
Forgatch, M. S., \& Stoolmiller, M. (1994). Emotions as contexts for adolescent delinquency. Journal of Research on Adolescence, 4(4), 601-614.

Galambos, N. L., Barker, E. T., \& Krahn, H. J. (2006). Depression, self-esteem, and anger in emerging adulthood: seven-year trajectories. Developmental Psychology, 42(2), 350-365.

doi:10.1037/0012-1649.42.2.350

Gottlieb, G. (2007). Probabilistic epigenesis. Developmental Science, 10(1), 1-11.

Granic, I., \& Patterson, G. R. (2006). Toward a comprehensive model of antisocial development: a dynamic systems approach. Psychological Review, 113(1), 101-131.

Hatano, G., \& Osawa, K. (1983). Digit memory of grand experts in abacus-derived mental calculation. Cognition, 15, 95-110.

Inhelder, B., \& Piaget, J. (1964). The early growth of logic in the child: Classification and seriation. London: Routledge \& Kegan Paul. (Original work published 1959)

Keating, D. P. (1990). Developmental processes in the socialization of cognitive structures. Development and learning: Proceedings of a symposium in honor of Wolfgang Edelstein on his 60th birthday (pp. 37-72). Berlin: Max Planck Institute.

Kobak, R., \& Sceery, A. (1988). Attachment in Late Adolescence: Working Models, Affect Regulation, and Representations of Self and Others. Child development, 59, 135-46. doi:10.2307/1130395.

Lamb, M. E., \& Lewis, C. (2005). The role of parent child relationships in child development. In M. H. Bornstein, \& M. E. Lamb (Eds.), Developmental psychology: an advanced textbook. (pp. 429-468). Mahwah, New Jersey: Lawrence Erlbaum.

Lerner, R. M. (2002). Concepts and theories of human development (3 ${ }^{\text {rd }}$ ed.). Mahwah, NJ: Lawrence Erlbaum Associates.

Lewis, M. (1997). The self in self-conscious emotions. Annals of the New York Academy of Sciences, 818 (1), $118-142$.

Lewis, M. D. (1995). Cognition-emotion feedback and the self organization of developmental paths. Human Development, 38, 71-102.

Lindsey, E. W., \& Mize, J. (2001). Contextual differences in parent-child play: Implications for children's gender role development. Sex Roles, 44(3-4),155-176. http://dx.doi.org/10.1023/A:1010950919451

Main, M., \& Goldwyn, R. (1994). Adult attachment classification system. Unpublished manual, University of California at Berkeley.

Main, M., Kaplan, N., \& Cassidy, J. (1985). Security in infancy, childhood and adulthood: A move to the level of representation. In I. Bretherton \& E. Waters (Eds.), Growing points of attachment theory and research. Monographs of the Society for Research in Child Development, 50 (1-2, Serial No. 209), 66-104.

Matsumoto et al. (2008). Culture, emotion regulation, and adjustment. Journal of Personality and Social Psychology, 94(6), 925-937. doi:10.1037/0022-3514.94.6.925

Moffitt, T. E. (1990). The neuropsychology of delinquency: A critical review of theory and research. In N. Morris \& M. Tonry (Eds.), Crime and justice (Vol. 12, pp. 99-169). Chicago: University of Chicago Press.

Paikoff, R. L., \& Brooks-Gunn, J. (1991). Do parent- child relationships change during puberty? Psychological Bulletin, 110, 47-66.

Patterson, G. R. (1982). A social learning approach: Vol. 3: Coercive family process. Eugene, OR: Castalia.

Patterson, G. R., \& Yoerger, K. (2002). A developmental model for early and late-onset antisocial behavior. In J. B. Reid, J. Snyder, \& G. R. Patterson (Eds.), Antisocial behavior in children and adolescents: A developmental analysis and model for intervention, (pp. 147-172). Washington, DC: American Psychological Association.

Patterson, G. R., Reid, J. B., \& Dishion, T. J. (1992). A social interactional approach: Vol. 4: Antisocial boys. Eugene: Castalia.

Reddy, V. (2003). On being the object of attention: implications for self-other consciousness. Trends in Cognitive Sciences, 7(9), 397-402.

Rogoff, B. (1990). Apprenticeship in thinking: Cognitive development in social context. New York: Oxford University Press. 
Rogoff, B. (2003). The cultural nature of human development. New York: Oxford University Press.

Rogoff, B., Mistry, J. Göncü, A., \& Mosier, C. (1993). Guided participation in cultural activity by toddlers and caregivers. Monographs of the society for Research in Child Development, 58(8), v-vi, 1-174; discussion 175-9.

Rutter, M. (2006). Genes and behavior: nature-nurture interplay explained (1 $1^{\text {st }} \mathrm{ed}$.). New York: Wiley.

Snyder J. J., \& Patterson G. R. (1995). Individual differences in social aggression: A test of a reinforcement model of socialization in the natural environment. Behavior Therapy, 26(2), 371-391. https://doi.org/10.1016/S0005-7894(05)80111-X

Snyder, J., Schrepferman, L., \& St. Peter, C. (1997). Origins of antisocial behavior: Negative reinforcement and affect dysregulation of behavior as socialization mechanisms in family interaction. Behavior Modification, 21, $187-215$

Snyder, J., Stoolmiller, M., Wilson, M., \& Yamamoto, M. (2003). Child anger regulation, parental responses to children's anger displays, and early child antisocial behavior. Social Development, 12, 335-360.

Spear, L. P. (2000). The adolescent brain and age-related behavioral manifestations. Neuroscience and Biobehavioral Reviews, 24, 417-463.

Sutherland, P. A. (1992). Cognitive development today: Piaget and his critics. London: Paul Chapman Publishing.

Teasdale J. D., \& Barnard P. J. (1993). Affect, cognition and change: Re-modelling depressive thought. Hove: Lawrence Erlbaum Associates.

Tomasello, Michael. (1999). The Human Adaptation for Culture. Annual Review of Anthropology, 28, 509-529. doi: 10.1146/annurev.anthro.28.1.509.

Vygotsky, L. S. (1978). Mind in society: The development of higher psychological processes. Cambridge, MA: Harvard University Press.

Walker, E., \& Tessner, K. (2008). Schizophrenia. Perspectives on Psychological Science, 3(1), 30-37.

Werker, J. F., \& Desjardins, R. N. (1995). Listening to speech in the first year of life: Experiential influences on phoneme perception. Current Directions in Psychological Sciences, 4, 76-81.

Wohlwill, J. F. (1969). The age variable in psychological research1. ETS Research Bulletin Series, i-44. doi:10.1002/j.2333-8504.1969.tb00579.x

Wohlwill, J. F. (1973). The Study of Behavioral Development. New York: Academic Press.

Wong, S., Bond, H. M., \& Mosquera, P. M. R. (2008). The influence of cultural value orientations on self reported emotional expression across cultures. Journal of Cross-Cultural Psychology, 39(2), 224-229. doi:10.1177/0022022107313866 